\title{
Relationship Between Nursing Students' Emotional Intelligence and Their Clinical Performance During Obstetrics and Gynaecologic Nursing Practical Training
}

\author{
Heba Abdel-Fatah Ibrahim¹, Wafaa Taha Ibrahim Elgzar 2, *, Rehab Elsayed Mohamed ${ }^{3}$, \\ Gihan Mohamed Mohamed Salem ${ }^{3}$ \\ ${ }^{1}$ Obstetrics and Woman Health Nursing, Benha University, Benha, Egypt \\ ${ }^{2}$ Obstetrics and Gynaecologic Nursing, Damanhour University, El-Behira, Egypt \\ ${ }^{3}$ Psychiatric Mental Health Nursing, Benha University, Benha, Egypt
}

Email address:

heba.abdelfattah@fnur.bu.edu.eg (H. Abdel-Fatah I.), Wafaa22006@yahoo.com (W. T. I. Elgzar)

${ }^{*}$ Corresponding author

\section{To cite this article:}

Heba Abdel-Fatah Ibrahim, Wafaa Taha Ibrahim Elgzar, Rehab Elsayed Mohamed, Gihan Mohamed Mohamed Salem. Relationship Between Nursing Students' Emotional Intelligence and Their Clinical Performance During Obstetrics and Gynaecologic Nursing Practical Training. American Journal of Nursing Science. Vol. 5, No. 6, 2016, pp. 240-250. doi: 10.11648/j.ajns.20160506.12

Received: September 20, 2016; Accepted: October 7, 2016; Published: November 7, 2016

\begin{abstract}
Nursing and midwifery are stressful professions due to the requirements of patients' care. They require a high degree of self-regulation and emotional intelligence (EI). The aim of this study was to identify the relationship between nursing students' EI and their clinical performance during obstetrics and gynecologic nursing practical training. A descriptive correlational research design was utilized. The study was conducted at the faculty of nursing, Benha University. A convenience sample of all third year female students $(\mathrm{N}=98)$ who were registered at reproductive health nursing course at the time of study was included. Two tools were used for data collection; first tool is a structured interview schedule to collect data about the subjects' demographic characteristics and the Schutte Self Report Emotional Intelligence Test. Second tool for clinical performance evaluation it composed of performance checklist for different obstetrics and gynecologic nursing procedures and evaluation of supportive clinical performance skills. There was a positive correlation $(\mathrm{p}<0.05)$ between students' EI and their total clinical performance skills. On the other hand, there was no statistically significant relation $(p>0.05)$ between students EI and their demographic characteristics. It can be concluded that there was a significant positive correlation between students' EI and their clinical performance skills. The topic of EI should be included as a basic component of nursing curriculum in order to develop students' EI abilities. Furthermore, Training courses and seminars about EI should be conducted for the nursing educators in order to develop and improve their own and students' EI skills.
\end{abstract}

Keywords: Clinical Performance, Emotional Intelligence, Nursing Students

\section{Introduction}

Nursing is a deeply human practice, especially in obstetrics and gynecologic branch. For any woman, it is extremely difficult to share obstetrics and gynecology information with anyone. However, in most circumstances she finds herself obligated to talk about the most private information with a nurse. At the same time, the nature of obstetric and gynecologic examination is embarrassing and unfavorable. This situation is exaggerated by two main factors inherited in almost all Arabic countries. First: the culture of silence surrounding the female complaints. Consequently, the majority of women have fixed believe that obstetric information should never be shared with anyone, even if she is in pain and/or danger. Second, the health care system in the majority of Arab countries does not support concepts such as the named midwife or integrated midwife. This means that the woman has to share her sensitive information with different 
staff each time she contacts health care. $[1,2]$

This embarrassing situation for the female client requires from the nurses and midwives to become competent at certain skills that can help her to build trustful nurse patient relationship. Building trustful relationship with the client is the first and most important skill in successful care. These skills include the aptitude to feel or imagine another persons' emotional experience (empathy), understand and regulate own emotions; acknowledge others' emotions, and the capability to manage emotions of self and others. All these abilities known as emotional intelligence (EI). [3, 4]

EI should be learned and developed during clinical training in the undergraduate education Victoroff and Boyatzis 2013 urged that teachers in clinical professions as medicine, nursing or dentists should consider EI as a key standard for student selection. They additionally added that many professional behaviors in health care may require abilities related to EI as: putting the patient needs ahead of their individual interests, fight to complete tasks at high standard nearly at all times, frequently assess their knowledge and skills, be familiar with their limitations and act with integrity. [5]

The psychologists Salovery and Mayer first used the word EI in 1990. They defined it as "the ability to process emotion-laden information competently and to use it to direct cognitive behavior as problem solving and to spotlight energy on requisite behaviors". [6] In other words, EI refers to "the one's capability to recognize own feelings and those of others and encompasses managing emotions effectively in ourselves and in our relationships". [7] It also involves possessing the capability for motivation, creativity and the aptitude to perform at an optimal level when completing tasks. EI also provides the ability to persist in face of setbacks and failures. [8]

In midwifery and nursing, EI is appreciated as one of the critical component of competency of care, which both influences institutional work and the building of effective nurse-patient relationships. These ultimately lead to more patient-centered care. According to Bulmer-Smith et al (2009) EI became popular within nursing literature but it is sometimes inadequately defined, overestimated and has not been actually measured. [9] In many circumstances EI is used as a predictor of communication skills, professional performance, team working as well as staff training. [10] It enables individuals to deal with life events and be more successful in personal relationships. This is particularly relevant to nursing and midwifery students. EI ensures that feelings are acknowledged and not dismissed or suppressed. Consequently, effective understanding of self and others may help the development of more insight in the complex situations that professional relationships bring within nursing and midwifery clinical training. [11]

Three main models have been proposed for EI. First, Goleman, 1995 viewed EI as "a set of skills and personal competences that enhance self-awareness, self-regulation, empathy and success in human relationships" [12]. Second, Mayer et al., 2003 defined EI-like academic intelligence "as an ability that can be learned and occurs when an individual can perceive, appraise and express emotions" [13]. Third, Bar-On, 2006 conceptualizes EI "as being similar to a set of personality traits and abilities". [14]

Mayer et al., 2003 had determined four main categories of EI. These categories were perceive emotions, using emotions, understanding emotions and managing emotions. [13] While Schutte et al., 1998 has proposed EI scale that contain three main categories. Namely, appraisal and expression of emotions, regulation of emotion and utilization of emotional information in thinking and acting. Each one of these three categories is divided to subcategories. First, appraisal and expression of emotions, which is the ability to detect and read emotions in self and others. This detection of emotion can be done in self through the ability to deeply recognize own feeling and conflicts. Moreover emotions can be detected on others through voices, pictures, facial expressions...etc. Second, regulation of emotion which is the ability to regulate and control emotion in both self and others. Therefore, the emotionally intelligent person can control emotions, even negative ones, and manage them to accomplish planned goals. Third, utilization of emotional information in thinking and acting. It can be defined as the aptitude to connect emotions to facilitate different cognitive activities. The emotionally intelligent person can benefit from his or her changing moods in order to best fit the duty at hand. This category can be further divided into four subcategories (flexible planning, creative thinking, motivation and redirected attention). [15, 16]

In nursing and midwifery practice, EI is acknowledged as an essential attribute of the effective nurse student in clinical training. [17] The difference in learning theoretical materials and practical one has been highlighted by Begley, 2006. He suggested that theoretical materials can be effectively educated in class rooms where, practical aspect together with its accompanied human skills including EI needs filed experience together with role model. [18] Consequently, nursing students need to be guided by good role model with high level of EI in their practical training. This involves approaching patients and colleagues in a constructive manner, listening to them carefully, effective communicating of information and giving skillful feedback to other team members. Consequently, the relation between EI and clinical performance is two-dimensional. On one hand, the student needs EI to perform better in clinical training and gain the client satisfaction. On the other hand, he needs to learn EI from the training experience through good role model and different training events. $[17,18]$

Two studies had emphasized on the importance of EI in clinical skills than intellectual intelligence, since people with high EI work better within team, and demonstrate higher interactive skills. They warning from nursing and midwifery students who have affective neutrality. According to them affective neutrality means lost ability to recognize the importance of emotional aspects in women care. Accordingly, they will be professionally disconnected and avoid emotions in their practices. $[19,20]$

Clinical performance is an important part of nursing 
education. It focuses on developing and applying the students' knowledge, attitudes, and skills required for future professional practice. [21] Clinical education provides students with unique teaching opportunities in which skills and theory are applied in the real life situations. Clinical training have a great role in improving students' learning, augments their sense of responsibility, bridging the theory practice gap, and provides them with a great chance to demonstrate nursing competences. [22] In clinical performance evaluation, it must be confirmed that the students have an effective professional and ethical conduct, establish good relationship with the patients, have the basic knowledge about clinical practice, prioritize the patients problems, perform nursing skills correctly, and apply critical thinking skill. [23]

EI also could help the midwife and nurse student to overcome harmful emotions in training places. Deery, 2005 highlights the critical role of midwifery and nursing student's supervisors in supporting them through emotional aspects of practice. He reported that clinical supervision could be successful in developing an increased self-awareness in nurse student. They can facilitate and support the emotional needs of their students. Accordingly, they can help their students in developing EI. Studies have concluded that EI can be learned later on life although it is developed early in childhood. They can be developed and changed in later life. Undeniably, EI can be developed with age and experience. Many students feel poorly prepared for the interpersonal and emotional situations that sometimes take place in their practice settings. Birth experiences should be used to develop the nurse emotional experience in the educational settings. Nursing educators also need to re-skill them in areas of EI and communication to deliver emotional sensitive care. [5, 20, 24]

\subsection{Significance of the Study}

Although extensive studies evaluating the role of EI in the workplace exist, examining the influence and importance of EI on the nursing performance is a more recent phenomenon. [9] EI appears to be essential for midwifery and nursing student because they need to learn how to manage their emotions, how to support women and provide high quality, satisfactory and women-centered care. Increasing EI will strengthen the students' capacity to deal with workplace pressures and develop effective relationships with colleagues and patients. Therefore, nursing educators should prepare their students for not only the clinical and theoretical demands of practice, but also the emotional challenges, which arise in difficult clinical situations. It is expected that midwifery and nursing students who are emotionally intelligent will manage emotions in practice to enhance both the mother and midwife experience. Therefore, today EI is acknowledged as an important skill to present high quality women care. Consequently, many midwifery schools have introduced some subjects in their curriculums that help to develop the student EI. However, in Egypt there is too little researches about the importance of EI in midwifery and nursing education. This have a negative impact on the quality of women care provided.

\subsection{Aim of the Study}

This study aimed to identify the relationship between nursing students' EI and their clinical performance during obstetrics and gynecologic nursing practical training.

\subsection{Research Questions}

Is there a relationship between nursing students' EI and their clinical performance?

Is there a relationship between nursing students' EI and their socio-demographic characteristics?

\section{Subjects and Methods}

\subsection{Operational Definition}

Clinical performance in this study refers to student achievement during the clinical training. It can be measured through two main items: First, assessment of the clinical procedure skills using observational checklist during the final practical exam. Second, assessment of the supportive clinical skills including: nursing care plan, communication, clinical reasoning/ problem solving, professional \& ethical conduct and oral/written presentations.

\subsection{Research Design}

Descriptive correlational research design was followed in this study.

\subsection{Setting}

This study was conducted at the faculty of nursing, Benha University, affiliated to ministry of higher education, Egypt.

\subsection{Subjects}

The study comprised a convenience sample of all third year female students who were registered at reproductive health nursing course at the time of study (first semester, academic year 2015/2016) and agreed to participate in the study. Total number was 98 female students, male students were excluded from the study because they did not have actual training in the hospitals they had only lab training.

\subsection{Tools of Data Collection: Two Tools Were Used for Data Collection}

\subsubsection{First Tool: Structured Interview Schedule}

It encompassed two major parts:

i. Part 1: It was developed by the researchers to elicit information about the socio-demographic characteristics of the studied subjects such as students' age, residence, marital status, parent education, and students' birth order.

ii. Part 2: The Schutte Self Report Emotional Intelligence Test (SSEIT)

It was originally developed by Salovey \& Mayer 1990 then it was modified by Schutte et al., 1998. [15] SSEIT was adapted and translated to Arabic language. The scale consists of 33 items, which are rated on a five-point Likert scale that 
ranges from 1 (never) to 5 (always). SSEIT includes three categories which are appraisal and expression of emotions (13 items), regulation of emotions (10 items) and utilization of emotions (10 items). The total SSEIT score ranged from 33 to 165. The subject is considered to have low EI (33 to 77), moderate EI (78 to 121) and high EI (122-165). The scale items were randomly distributed in order to avoid leading sentences. The items distributed according to table 1:

Table 1. Distribution of SSEIT categories and questions numbers.

\begin{tabular}{ll}
\hline Categories & Questions number \\
\hline $\begin{array}{l}\text { Appraisal and expression of } \\
\text { emotions }\end{array}$ & $2,4,5,9,15,18,19,22,25,26,29,32$ and 33 \\
Regulation of emotions & $1,7,12,14,16,20,21,23,27$ and 31 \\
Utilization of emotions & $3,6,8,10,11,13,17,24,28$ and 30 \\
\hline
\end{tabular}

\subsubsection{Second Tool: Evaluation of Clinical Performance: It Composed of Two Main Parts}

i. Part I: Clinical/Procedural skills.

Performance checklist for different obstetrics and gynecologic nursing procedures which is developed by obstetrics and women health nursing department at faculty of nursing/ Benha University. It contains checklists for all obstetrics and gynecologic nursing procedures in (antenatal, labor, post-partum, gynecology and family planning). Each checklist contains detailed steps of the procedures then the total score is calculated from 20. It was used to assess the student procedural performance during the final practical exam.

ii. Part II: Supportive clinical performance skills.

It was developed by the researchers after reviewing of the related literature to evaluate students' supportive clinical performance skills. It includes five components, which are nursing care plan (5 items), communication (4items), clinical reasoning/ problem solving (5items), professional \& ethical conduct (8items), and oral/written presentations ( 7 items). Each item rated on a five-point Likert scale that ranges from 1 (never) to 5 (always). The total score of 29 items ranged from 29 to 145 . The higher grad indicate better performance.

\subsection{Tools Validity and Reliability}

All tools were tested for content validity by a jury of five expertise in the obstetrics and gynecologic nursing as well as psychiatric and mental health nursing and one expert from the biostatistics field. Modifications were done accordingly based on their judgment. Reliability was done by Cronbach's Alpha coefficient test which revealed that each of the two tools consisted of relatively homogenous items as indicated by the moderate to high reliability (internal consistency) of each tool $(\mathrm{SSEIT}=0.71$ and clinical performance evaluation $=0.87)$.

\subsection{Ethical Considerations}

This research was conducted under the approval of Ethics Committee/ faculty of nursing/ Benha University. Informed oral consent was obtained from each student after explanation of the study purpose and importance. They were reassured that their responses would not affect their grades. They also were informed that their information would be confidential and would be used only for research purpose. In addition, they were ensured that they had the right to refuse participation on the study and that they had the right to withdraw from the study at any time.

\subsection{Field of Work}

Official permissions were obtained from the responsible authorities of the faculty of nursing, Benha University to conduct the study after explaining its purpose.

Pilot study was carried out on randomly selected $10 \%$ students not included in the actual study.

First tool was administered to the students at the beginning of the semester. The students' answering of the study tool was attended by one of the researchers to ensure that all required information in the sheets was completed. Second tool part I was completed during the final practical exam. Part II was completed during the practical training during the whole semester. The data was collected from the beginning of the first semester, academic year 2015/2016 until its end including the examination period.

\subsection{Statistical Analysis}

The Statistical Package for Social Sciences (SPSS) version 20 was used for data analysis. Descriptive statistics and correlation coefficients were used to answer the research questions. Descriptive statistics (frequency, percentage, arithmetic mean and standard deviation) were used to describe characteristics of the subjects including: socio-demographic and academic characteristics and the levels of EI. One sample T-test was used to examine the differences between the students. Monte Carlo test was used to examine the relations between variables if there is small expected value. A statistically significant difference was considered at $p$-value $\mathrm{p} \leq 0.05$ and a highly statistically significant difference was considered at $\mathrm{p}$-value $\mathrm{p} \leq 0.001$.

\section{Results}

Table 2. Demographic characteristics of the study subjects ( $n=98)$.

\begin{tabular}{lll}
\hline Items & N & \% \\
\hline Residence & 44 & 44.9 \\
Urban & 54 & 55.1 \\
Rural & & \\
Marital status & 86 & 87.8 \\
Single & 12 & 12.2 \\
Married & & \\
Mothers' level of education & 16 & 16.4 \\
Basic education & 51 & 52.0 \\
Secondary education & 26 & 26.5 \\
University education & 5 & 5.1 \\
Post graduate & & \\
Mothers' job & 67 & 68.4 \\
House wife & 31 & 31.6 \\
Employee & & \\
Birth order & 68 & 69.4 \\
$1-2$ &
\end{tabular}




\begin{tabular}{lll}
\hline Items & N & \% \\
\hline $3-4$ & 26 & 26.5 \\
5 and more & 4 & 4.1 \\
$\begin{array}{l}\text { Mean } \pm \text { SD } \\
\text { Age in years }\end{array}$ & $2.08 \pm 1.24$ & \\
Mean \pm SD & $21.06 \pm 0.78$ \\
\hline
\end{tabular}

Table 2 represents socio demographic characteristics of the study subjects. It was clear that, $55.1 \%$ of the students were rural areas residence. As regards to marital status, $87.8 \%$ were single. Concerning their mothers' level of education, $52 \%$ of them had secondary education. Also $68.4 \%$ of the students' mothers were house wives. Moreover, $69.4 \%$ of them were born first or second among their siblings. The students' mean age was $21.06 \pm 0.78$ years.

Table 3. Mean and standard deviations of the students' emotional intelligence main categories $(n=98)$.

\begin{tabular}{l|llll}
\hline Categories & Maximum score & Mean & standard deviation & t \\
\hline Appraisal and expression of emotions & 65 & 43.57 & 6.63 & 65.04 \\
Regulation of emotions & 50 & 33.84 & 6.69 & $<0.001 * *$ \\
Utilization of emotion & 50 & 33.76 & 6.60 & 50.07 \\
Total score of emotional intelligence & 165 & 110.5 & 17.46 & 50.57 \\
\hline
\end{tabular}

The test used is one sample $\mathrm{t}$ test

**A highly statistical significant difference $(\mathrm{p} \leq 0.001)$

Table 3 displays that, the mean score of students' EI main categories were $(43.57 \pm 6.63,33.84 \pm 6.69$, and $33.76 \pm 6.60)$ related to appraisal and expression of emotions, regulation of emotions and utilization of emotions respectively. In addition, the total EI mean score was $110.5 \pm 17.46$. It is observed that, there was a highly statistical significant difference between the students in all categories of their EI $(\mathrm{p}<0.001)$.

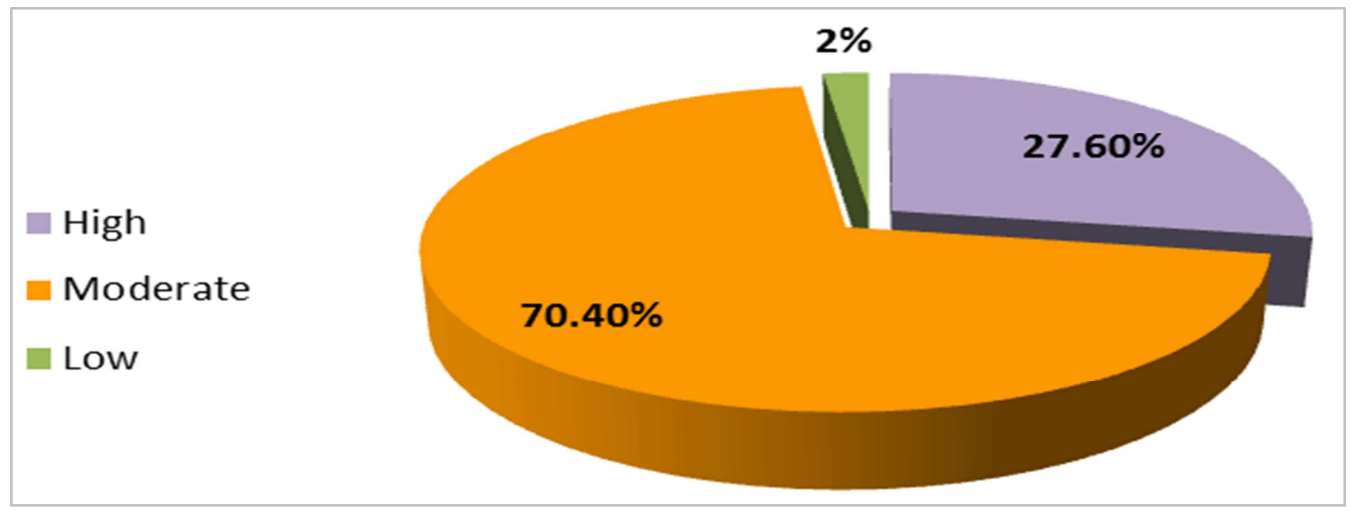

Figure 1. Distributions of the students according to their total emotional intelligence ( $n=98)$.

Figure 1 reveals that $70.40 \%$ of the students had moderate level of emotional intelligence. Where, only $2 \%$ of them had low level of emotional intelligence.

Table 4. Mean and standard deviations of the students' clinical performance skills (procedural and supportive clinical skills) ( $\mathrm{n}=98$ ).

\begin{tabular}{llllc}
\hline Item & Maximum score & Mean & Standard deviation & t \\
\hline Clinical/Procedural skills & 20 & 15.25 & 3.77 & 97.3 \\
$\begin{array}{l}\text { Supportive clinical skills } \\
\text { Nursing care plan }\end{array}$ & & & \\
Communication & 25 & 18.83 & 3.62 & 78.52 \\
Clinical reasoning and problem solving & 20 & 15.04 & 2.37 & 66.79 \\
Professional and ethical conduct & 25 & 18.04 & 3.58 & $80.001 * *$ \\
Presentation & 40 & 33.61 & 4.79 & 80.67 \\
Total Supportive clinical skills & 35 & 25.79 & 3.85 & 95.5 \\
Total clinical performance score & 145 & 110.73 & 9.95 & 71.40 \\
\hline
\end{tabular}

The test used is one sample t test

**A highly statistical significant difference $(\mathrm{p} \leq 0.001)$

Table 4 clarifies that; the mean score of students' clinical/procedural skills was (15.25 \pm 3.77$)$. Regarding to supportive clinical skills, the mean score were $(18.83 \pm 3.62,15.04 \pm 2.37,18.04 \pm 3.58,33.61 \pm 4.79,25.79 \pm 3.85$ and $110.73 \pm 9.95)$ related to nursing care plan, communication, clinical reasoning and problem solving, professional and ethical conduct, presentation and total supportive clinical skills respectively. Finally, the total clinical performance mean score was 117.98 \pm 18.86 . 
Table 5. Correlation coefficient between students' emotional intelligence and their clinical performance skills ( $n=98$ ).

\begin{tabular}{|c|c|c|c|c|c|c|c|c|}
\hline \multirow{3}{*}{ Clinical skills } & \multicolumn{8}{|c|}{ Emotional intelligence categories } \\
\hline & \multicolumn{2}{|c|}{$\begin{array}{l}\text { Appraisal and expression of } \\
\text { emotions }\end{array}$} & \multicolumn{2}{|c|}{$\begin{array}{l}\text { Regulation of } \\
\text { emotions }\end{array}$} & \multicolumn{2}{|c|}{$\begin{array}{l}\text { Utilization of } \\
\text { emotions }\end{array}$} & \multicolumn{2}{|c|}{$\begin{array}{l}\text { Total emotional } \\
\text { intelligence }\end{array}$} \\
\hline & $\mathbf{r}$ & $\mathbf{P}$ & $\mathbf{r}$ & $\mathbf{P}$ & $\mathbf{r}$ & $\mathbf{P}$ & $\mathbf{r}$ & $\mathbf{p}$ \\
\hline Clinical/Procedural skills & 0.15 & $>0.05$ & 0.21 & $<0.05^{*}$ & 0.24 & $<0.05^{*}$ & 0.23 & $<0.05^{*}$ \\
\hline \multicolumn{9}{|l|}{ Supportive clinical skills } \\
\hline Nursing care plan & 0.005 & $>0.05$ & 0.007 & $>0.05$ & 0.20 & $<0.05^{*}$ & 0.09 & $>0.05$ \\
\hline Communication & 0.21 & $<0.05^{*}$ & 0.07 & $>0.05$ & 0.24 & $<0.05^{*}$ & 0.23 & $<0.05^{*}$ \\
\hline Clinical reasoning and problem solving & 0.01 & $>0.05$ & 0.21 & $<0.05^{*}$ & 0.04 & $>0.05$ & 0.07 & $>0.05$ \\
\hline Professional and ethical conduct & 0.20 & $<0.05^{*}$ & 0.01 & $>0.05$ & 0.05 & $>0.05$ & 0.24 & $<0.05^{*}$ \\
\hline Presentation & 0.23 & $<0.05^{*}$ & 0.008 & $>0.05$ & 0.14 & $>0.05$ & 0.01 & $>0.05$ \\
\hline Total Supportive clinical skills & 0.05 & $>0.05$ & 0.14 & $>0.05$ & $0 . \mathrm{r} 22$ & $<0.05^{*}$ & 0.23 & $<0.05^{*}$ \\
\hline Total clinical skills & 0.04 & $>0.05$ & 0.01 & $>0.05$ & 0.20 & $<0.05^{*}$ & 0.225 & $<0.05^{*}$ \\
\hline
\end{tabular}

*A statistical significant difference $(\mathrm{p} \leq 0.05)$

Table 5 portrays that; there was a positive correlation coefficient between students' total clinical performance skills and their total EI and utilization of emotions $(\mathrm{r}=0.22, \mathrm{p}<0.05$, $\mathrm{r}=0.20, \mathrm{p}<0.05$ ) respectively, as well as between total supportive clinical skills and total EI and utilization of emotions $(\mathrm{r}=0.23, \mathrm{p}<0.05, \mathrm{r}=0.22, \mathrm{p}<0.05)$ respectively. In addition, there was a positive correlation coefficient between communication and appraisal, utilization of emotions and total EI $(\mathrm{r}=0.21, \mathrm{p}<0.05, \mathrm{r}=0.24, \mathrm{p}<0.05, \mathrm{r}=0.23, \mathrm{p}<0.05)$ respectively. Where, professional and ethical conduct was significantly correlated with appraisal and expression of emotions $(\mathrm{r}=0.20, \mathrm{p}<0.05)$ as well as total clinical performance skills $(r=0.24, p<0.05)$. Presentation skills was significantly correlated with appraisal and expression of emotions $(\mathrm{r}=0.23, \mathrm{p}<0.05)$ respectively. Finally, clinical reasoning and problem solving was significantly correlated with regulation of emotions $(\mathrm{r}=0.21, \mathrm{p}<0.05)$.

Table 6. Correlation coefficient between students' total emotional intelligence and their clinical performance score, age and birth order $(n=98)$.

\begin{tabular}{lllll}
\hline \multirow{2}{*}{$\begin{array}{l}\text { demographic } \\
\text { characteristics }\end{array}$} & \multicolumn{2}{l}{$\begin{array}{l}\text { Total emotional } \\
\text { intelligence }\end{array}$} & \multicolumn{2}{l}{$\begin{array}{l}\text { Total clinical } \\
\text { performance }\end{array}$} \\
\cline { 2 - 5 } & $\mathbf{r}$ & $\mathbf{P}$ & $\mathbf{r}$ & $\mathbf{P}$ \\
\hline Age & 0.06 & $>0.05$ & 0.06 & $>0.05$ \\
Birth order & 0.08 & $>0.05$ & 0.09 & $>0.05$ \\
\hline
\end{tabular}

Table 6 illustrates that; there was no significant correlation coefficient between students' age and lor birth order and total $\mathrm{EI}(\mathrm{r}=0.06, \mathrm{p}>0.05)$ and $(\mathrm{r}=0.08, \mathrm{p}>0.05)$ respectively.

Table 7. The relationship between the students' demographic characteristics and their total emotional intelligence ( $n=98$ ).

\begin{tabular}{|c|c|c|c|c|c|c|c|c|}
\hline \multirow{3}{*}{ Item } & \multicolumn{6}{|c|}{ Total emotional intelligence } & \multirow{3}{*}{ Mc } & \multirow{3}{*}{$\mathbf{P}$} \\
\hline & \multicolumn{2}{|c|}{ Low $(n=2)$} & \multicolumn{2}{|c|}{ Moderate(n=69) } & \multicolumn{2}{|c|}{$\operatorname{High}(n=27)$} & & \\
\hline & $\mathbf{N}$ & $\%$ & $\mathbf{N}$ & $\%$ & $\mathbf{N}$ & $\%$ & & \\
\hline \multicolumn{9}{|l|}{ Residence } \\
\hline Urban & 1 & 50.0 & 31 & 44.9 & 12 & 44.4 & \multirow[t]{3}{*}{0.02} & \multirow[t]{3}{*}{$>0.05$} \\
\hline Rural & 1 & 50.0 & 38 & 55.1 & 15 & 55.6 & & \\
\hline \multicolumn{7}{|l|}{ Marital status } & & \\
\hline Single & 2 & 100.0 & 61 & 88.4 & 23 & 85.2 & \multirow[t]{3}{*}{3.41} & \multirow[t]{2}{*}{$>0.05$} \\
\hline Married & 0 & 0.0 & 8 & 11.6 & 4 & 14.8 & & \\
\hline \multicolumn{8}{|c|}{ Mother' level of education } & \\
\hline Basic education & 1 & 50.0 & 13 & 18.8 & 2 & 7.4 & \multirow{5}{*}{12.12} & \multirow{4}{*}{$>0.05$} \\
\hline Secondary education & 0 & 0.0 & 37 & 53.6 & 14 & 51.9 & & \\
\hline University education & 1 & 50.0 & 14 & 20.4 & 11 & 40.7 & & \\
\hline Post graduate & 0 & 0.0 & 5 & 7.2 & 0 & 0.0 & & \\
\hline \multicolumn{8}{|l|}{ Mother' job } & \\
\hline House wife & 2 & 100.0 & 50 & 72.5 & 15 & 55.6 & \multirow[t]{2}{*}{3.08} & \multirow[t]{2}{*}{$>0.0$} \\
\hline Work & 0 & 0.0 & 19 & 27.5 & 12 & 44.4 & & \\
\hline
\end{tabular}

$\mathrm{Mc}=$ monte carlo test

Table 7 shows that; there was no a statistically significant relation between students EI and their residence, marital status, mothers education and job.

\section{Discussion}

Nursing and midwifery is a stressful profession due to requirements of patients' care. It requires a high degree of self-regulation and EI. Especially when this care is provided 
to the women during the stress of pregnancy and childbirth. Nursing students work as caregivers in clinical areas early in their education. Therefore, EI is required to help them to control their emotions; as inability to control emotions can lead to increase anxiety, stress and negatively affect the quality of care. [25] Emotion is fundamental to nursing and midwifery practice consequently, EI is considered as an important skill for nurses. It can affect the quality of their work including clinical decision-making, critical thinking, implementation of nursing care plan, communication and knowledge use in practice. Teaching staff in nursing schools should know that nursing students have different levels of emotional maturity that help them to overcome a lot of stress present in this profession. They should also consider that the way to deal with emotions is attainable to a noticeable extent through learning. [26]

The present study has revealed that, the mean score of students' EI was $110.5 \pm 17.46$ indicating moderate EI. This finding is in the same line with Rice, 2015, Codier and Odell, 2014, Mahmoud et al., 2013, Beauvais et al., 2013, and Beauvais et al., 2011. [27, 28, 29, 30, 31] Where the first, had studied "predictors of successful clinical performance in associate degree nursing students. The second, had measured" EI ability and grade point average in nursing students". The third, had studied "EI among baccalaureate students at the faculty of nursing, Alexandria University". The fourth had studied "the factors related to academic success among nursing students". The fifth, studied "EI and nursing performance among nursing students". They stated that, the mean score for EI among their study participants was within moderate level. This agreement between the present study result and this group of studies may be due to the fact that, all of them were carried out on students with limited clinical experience and young age. It is strongly acknowledged that EI as human attribute improves through experience and age. [32]

On the contrary, at least three studies found to disagree with the present study result. First, that of Al-Tamimi and Al-Khawaldeh, 2016 [33] who studied "EI and its relation with the social skills and religious behavior of female students at Dammam University in the light of some variables". They reported that the average grade for the EI among arts faculty female students was in high level. Second, that of Mohzan et al., 2013 [34] who studied "the influence of EI on academic achievement". He found that the students of the faculty of education, technology MARA University had high level of EI. Third, that of Singaravelu, 2007 [35] who had studied" EI of education students at primary level". He had reported that the EI of education students was high. This discrepancy between the present study and the latter three studies might be attributed to the educational differences in the present study and the contrary group. Where, the present study deals with nursing student, the other three studies deal with Arts and education students, whose respondents are future educators, with different age groups and different educational courses. Education and arts students mostly learn pedagogical courses which may include some topics on how to be emotionally intelligent. In addition, Mohzan et al., study deals with both male and female students, while the present study deals with female students only.

Regarding research question 1, the present study results revealed a positive correlation between students' total EI and their clinical performance skills. These results indicate the necessity and importance of emotions in decision-making for proper clinical performance and the effectiveness of EI in enhancing skills necessary for obstetrics and gynecologic nursing students. The results of the present study agree with at least five other researches. First, Rankin 2013 [36] who had studied " EI: enhancing values-based practice and compassionate care in nursing". Second, Tafazoli et al., 2012 [37] who investigated "the relationship between EI and clinical performance in training field in midwifery students". Third, Por et al., 2011 [25] who studied " EI: Its relationship to stress, coping, well-being and professional performance in nursing students". Fourth, Beauvais et al., 2011 [31] who had studied "the EI and nursing performance among nursing students". Fifth, Codier et al., 2008 [38] who measured "the EI of clinical staff nurses". The five studies had found significant positive correlations between clinical performance and EI although different measuring tools were used to measure EI and clinical performance. This result seems to be logic because emotional intelligence by definition deals with appraisal and expression of emotions, regulation of emotion and utilization of emotional information in thinking and acting. [15] Consequently, students with high EI are expected to demonstrate higher levels of interactive skills, are more co-operative and work more effectively within team. They also expected to be more successful in nurse -patient relationship. [19, 20]

Both of Gordon-Handler, 2009 and Talarico et al., 2008 $[39,40]$ findings had contradicted the present study finding. The former had investigated "the relationship between EI and clinical performance in an occupational therapy training program". The latter had studied "EI and its correlation to performance as a resident, on medical college students". Their results indicated that there were no significant correlation between the students' EI $\mathrm{s}$ and their clinical performance. The cause of the difference in findings between these studies and that of the present research is probably due to the difference in the comparative educational program. While the medical and occupational therapist students depend on their hands in their clinical performance skills rather than social and communication skills. However, nursing students depend on interpersonal relationship and social communication skills, as they are the milestone of their clinical performance.

The results of this study also showed that, of the three sub-scales of EI (appraisal and expression of emotions, regulation of emotions and utilization of emotions); there was a significant correlation between utilization of emotions and total clinical performance. This result is congruent with previously mentioned Beauvais et al., 2011 study. [31] In his study, of the four EI subscales, (receiving emotions, 
understanding emotions, using emotions, and managing emotions) the only significant correlation found was between understanding emotion and total clinical performance. The researchers of the present study urged that utilization of emotions is the most important aspect in clinical training because how to use emotions will affect all aspects of clinical training competencies as: communication, presentation, problem solving and gaining patients' cooperation. On the other hand, Al-Hamdan et al., 2016 and Bakr and Safaan, 2012 [41, 42] checked the relationship between EI and nurses performance. Both of them demonstrated a significant positive relationship between all subscales of EI and nurses performance. This discrepancy between the present study and the latter studies might be related to the age and experience differences between the studies subjects. Where, the present study deals with student nurses with young age and limited experience, the latter studies deals with mature registered nurses with long experience. It is strongly acknowledged that age and experience play an important role in EI acquisition.

The findings of the present study also revealed that there was positive correlation between communication as an integral part of supportive clinical skills and appraisal of emotions, utilization of emotions and total EI. This result was consistent with the researches conducted by Cherry et al., 2014, Hacettepe and Kose, 2013 and Lee and Ok, 2013. [43, 44, 45] The first had studied "validating relationships among attachment, EI and clinical communication". The second had studied "evaluation of EI and communication skills of health care manager candidates". The third had studied "The relationship between EI and communication skill, clinical competence \& clinical practice stress in nursing students". They found a significant positive relationship between communication skills and total EI among study participants. In addition, nursing instructors make stress on communication and social skills as important factor in acquiring clinical performance skills. This result is seems to be convincing because prerequisite for effective communication is appraisal of own and others emotions.

The findings of this study indicated that, clinical reasoning and problem solving was significantly correlated with one component of EI (regulation of emotions). This result is consistent with Mi-Ran and Su-Jeong, 2015 [46] who had studied " nursing students' EI and coping strategies" and with that previously mentioned Por et al., 2011study. [25] Both of them demonstrated a significant positive relationship between problem solving coping and EI. The findings suggest that regulation of own and others' emotions assist nursing students to adopt active and effective coping strategies when dealing with problems.

Regarding to professional and ethical conduct, the present study reported that EI were significantly correlated with professional and ethical conduct. This finding is in the same line with Cabral and Carvalho, 2014 and Angelidis and Ibrahim, 2011. [47, 48] The former had studied " EI and ethics on organizations". The latter had studied "the impact of EI on the ethical judgment of managers". They concluded that EI was significantly correlated with individual ethics, perceptions of other's ethics and ethical judgment. Also Agarwal and Chaudhary, 2013 [49] who studied " role of EI in ethical decision making", stated that EI enhance our personality and moral reasoning to figure out what is right and wrong for the human being. EI help in the personality maturation, consequently, it directs the person to take moral decisions and act professionally regardless of his own interests.

Regarding research question 2, the findings of this study indicated that, there was no significant correlation between the students' demographic characteristics including birth order and their total EI. This result is similar to the results of two studies. First, Miri et al., 2013 [50] who had studied "the relationship between EI and academic stress in medical sciences students". Second, is the previously mentioned study of Tafazoli et al., 2012 [37]. Both studies indicated that, there was no significant relationship between the birth order and EI level. The result of this group of studies may be justified by the theory postulated that EI is a mental ability to implicate and apply the emotional information which is partly intrinsic and partly acquired during life experiences. [50]

Additionally, the current study results confirmed that there was no significant relationship between students' age and their total EI. The results of the present study agree with the results of Ghanimat et al., 2013, Saeed et al., 2013 and Adeyemo, 2008. [51, 52, 53] The first had analyzed "the relationship between demographic characteristics and EI in female student at Islamic Azad University of Tabriz". The second had studied "EI of nurses in general and intensive care units". The third had studied "demographic characteristics and EI among workers in some selected organizations" .This group of studies found no significant relationship between the age of the studied subjects and their total EI score.

On the other hand both Snowden et al., 2015 and Ungur and Karagozoglu, 2013 [32, 54] had reported different results Where, the first had studied the relationship between EI, previous caring experience and mindfulness in student nurses and midwives. The second had studied "the relationship between EI, social physique anxiety and life satisfaction in physical education and sports students". Both studies emphasized that the age of the student has significant relation with total EI. Furthermore, a very recent study conducted by Srinivasan and Umesh Samuel, 2016 [55] had studied "EI of staff nurses working in Villupuram district". Emphasized that EI increased with age. The difference between the present study findings and the latter group studies might be related to the fact that all the studied subjects in the current study had close or the same age, as all of them were third year students. Therefore, there is no clear age variation that can clarify the correlation between the students' EI and their age.

Regarding to marital status no significant difference was found between married and unmarried students and their total EI score. In this regard Saeed et al., 2013 and Saeid et al., $2013[52,56]$ checked the relationship between this variable and the total score of EI. They found no significant relationship between these two variables. On the contrary 
with the present study result; Ealias and George, 2012 [57] who had studied the EI and job satisfaction. They found a significant difference on the EI between married and unmarried study subjects in which $75 \%$ of the married respondents having high EI. In another study, Pande, 2010 [58] had evaluated "the characteristics and EI among workers in organizations in Rajasthan state". He reported that, married respondents had higher level of EI than unmarried ones. The difference between the present study's findings and the latter two studies might be attributed to the fact that the current study included a small percentage of married respondents, which represent only $12 \%$ of the total respondents, while in the contradictory studies more than $50 \%$ of the respondents were married and in different age groups.

Based on the present study findings, there was no statistically significant relation between students EI and their residence. This result is in line with the studies of Gangal and Singh, 2012. [59] They had studied "EI of teacher trainee of Meerut city" and found out that the rural and urban studied subjects do not differ significantly in relation to their EI. The finding is also in agreement with the findings of the previously mentioned Singaravelu, 2007 [35] study. He found no significant difference in the EI of urban and rural studied respondents.

On the other hand, at least two studies found to be in contrary with the present study result. First, that of Adsul, 2013 [60] who had studied "a comparative study of urban and rural students on EI and adjustment". He found a significant difference between urban and rural students on the different areas of EI, Where urban students had better EI than rural students. Second that of Punia and Sangwan, 2011 [61] who had studied "EI and social adaptation of school children". He stated that urban children comparatively had better EI against rural children. This discrepancy between the present study and the latter two studies might be attributed to the cultural and age group differences in the present study and the contrary group.

\section{Conclusion}

Based on the results of the present study, and answering of research questions it can be concluded that, obstetrics and gynecologic nursing students at the Faculty of Nursing, Benha University had moderate levels of EI. Furthermore, there was positive correlation between students' EI and their clinical performance skills. In addition, there is no statistically significant relation between students EI and their demographic characteristics.

\section{Recommendations}

- Training courses and seminars about EI should be conducted for the nursing educators in order to develop and improve their own and students' EI skills.

- The topic of EI should be included as a basic component of nursing curriculum in order to develop students' EI abilities
- Replication of the present study on larger sample, different settings and courses

- Further study is required to evaluate the effect of implementing intervention programs to develop and enhance nursing students' EI abilities.

\section{Acknowledgements}

The researchers would like to express gratitude and appreciations to the students who participated in this study for their effective cooperation.

\section{References}

[1] Hasnain, M., Connell, K. J., Menon, U., and Tranmer, P. A. Patient-centered care for Muslim women: Provider and patient perspectives, Journal of Women's Health, 2011; 20(1): 73-83.

[2] Nasir, L. S and Abdul-Haq, A. K. Caring for Arab Patients A Biopsychosocial Approach. Sultan qaboos university medical journal, 2008; 8(2): 233-234. Available at http://www.radcliffeoxford.com/books/bookdetail.aspx?ISBN $=1846191823$

[3] Zaki, J., and Ochsner, K. N. The neuroscience of empathy: progress, pitfalls and promise, nature neuroscience journal, 2012; 15(5): 675-680.

[4] Ezzatabadi, M. R., Bahrami, M. A., Hadizadeh, F., Arab, M., Nasiri, S., Amiresmaili, M., and Tehrani, G. A. Nurses' emotional intelligence impact on the quality of hospital services, Iran Red Crescent Med J. 2012; 14(12): 758-763. Available at http://www.ncbi.nlm.nih.gov/pmc/articles/PMC3587863/

[5] Victoroff, K. Z., and Boyatzis, R. E. What is the relationship between emotional intelligence and dental student clinical performance? Journal of dental education, 2013; 77(4): 416-426.

[6] Salovey, P., Mayer, J. D., and Caruso, D. The positive psychology of emotional intelligence, In C. R. Snyder \& S. J. Lopez (Eds.), Handbook of positive psychology, Oxford University Press, 2002: 159-171.

[7] Roe, K. Leadership, 'Practice and Perspectives', Oxford University Press, Oxford. 2014.

[8] Gorgens- Ekermans, G., and Brand, T. Emotional intelligence as a moderator in the stress-burnout relationship: a questionnaire study on nurses, Journal of clinical nursing; 2012; 21(15): 2275-2285.

[9] Bulmer- Smith, K., Profetto-McGrath, J., and Cummings, G. G. Emotional intelligence and nursing: An integrative literature review, International Journal of Nursing Studies, 2009; 46 (12): 1624-1636.

[10] Joseph, D. L., and Newman, D. A. Emotional intelligence: an integrative meta-analysis and cascading model, Journal of Applied Psychology, 2010; 95(1): 54-78.

[11] Akerjordet, K., and Severinsson, E. Emotional intelligence: Part 1: the development of scales and psychometric testing, Nursing and Health Sciences, 2009; 11(1): 58-63. 
[12] Goleman, D. Emotional Intelligence, New York, NY, England: Bantam Books, Inc.1995.

[13] Maye,r J., Salovey, P., and Caruso, D. Measuring emotional intelligence with the MSCIT, Emotion. 2003; 3(1): 97-105.

[14] Bar-On R. The Bar On model of emotional-social intelligence. Psicothema, 2006; 18: 13-25.

[15] Schutte, N. S., Malouff, J. M., Hall, L. E., Haggerty, D. J., Cooper, J. T., Golden, C. J., and Dornheim, L. Development and validation of a measure of emotional Intelligence, Personality and Individual Differences. 1998; 25(2):167-177.

[16] Gignac, G. E., Palmer, B. R., Manocha, R., and Stough, C. An examination of the factor structure of the schutte self-report emotional intelligence (SSREI) scale via confirmatory factor analysis, Personality and Individual Differences, 2005; 39(6): 1029-1042.

[17] Jordan, P. J., and Troth, A. C. Managing emotions during team problem-solving: emotional intelligence and conflict resolution, Human Performance, 2004; 17(2): 195-218.

[18] Begley, A. M. Facilitating the development of moral insight in practice: teaching ethics and teaching virtue, Nursing Philosophy, 2006; 7(4): 257-265.

[19] Hunter, B. The emotional context of midwifery: In: Fraser D, Cooper M. (Eds.), Myles textbook for midwives, Churchill and Livingstone: London. 2009

[20] Patterson, D., and Begley, A. M. An exploration of the importance of emotional intelligence in midwifery, Evidence Based Midwifery, 2011; 9(3): 128134. Available at https://www.rcm.org.uk/learning-and-career/learning-and-rese $\mathrm{arch} / \mathrm{ebm}$-articles/an-exploration-of-the-importance-of-emotio nal

[21] Singapore Nursing Board. Standards for Clinical Nursing Education, May 2012 available at http://www.healthprofessionals.gov.sg/content/dam/hprof/snb/ docs/publications/SNB-Standards\%20for\%20Clinical\%20Nur sing\%20Education\%202012.pdf

[22] Pazargadi, M., Ashktorab, $\mathrm{T}$ and Khosravi, S. Nursing Students' Experiences on the Evaluating Role of Their Clinical Educators: a Qualitative Study, Procedia - Social and Behavioral Sciences 46, 2012: 5849-5857.

[23] Khosravi, S, Pazargadi, M and Ashktorab, T. Nursing Students viewpoints on challenges of student assessment in clinical Settings: A Qualitative Study. Iran J Educ Med. 2010;11(7): 736-48.

[24] Deery, R. An action-research study exploring midwives' support needs and the affect of group clinical supervision, Midwifery, 2005; 21(2): 161-165.

[25] Por, J., Barriball, L., Fitzpatrick, J., and Roberts, J. Emotional intelligence: Its relationship to stress, coping, well-being and professional performance in nursing students. Nurse Education Today 2011;31(8): 855-860.

[26] Barkhordari, M., and Rostambeygi, P. Emotional intelligence in nursing students Journal of advances in Medical education \& professionalism. 2013; 1(2): 46-50.

[27] Rice, E. Predictors of Successful Clinical Performance in Associate Degree Nursing Students, Nurse Education, 2015; 40(4):207-211.
[28] Codier, E., and Odell, E. Measured emotional intelligence ability and grade point average in nursing students, Nurse Education Today, 2014; 34(4): 608-612.

[29] Mahmoud, H. M., Abd El-Dayem, S. M., and Mousa M. A. Emotional Intelligence among Baccalaureate Students at the Faculty of Nursing, Alexandria University, Egypt: A Cross-sectional Study, Journal of Education and Practice. 2013; 4(27): 49-61.

[30] Beauvais, A. M., Stewart, J. G., DeNisco, S., and Beauvais, J. E. Factors related to academic success among nursing students: A descriptive correlational research study, Nurse Education Today. 2013; 34(6): 918-23 http://dx.doi.org/10.1016/j.nedt.2013.12.005

[31] Beauvais, A. M., Brady, N., O'Shea, E. R., and Griffin, M. T. Emotional intelligence and nursing performance among nursing students, Nurse Education Today, 2011; 31(4): 396-401.

[32] Snowden, A., Stenhouse, R., Young, J., Carver, H., Carver, F., and Brown, N. The relationship between emotional intelligence, previous caring experience and mindfulness in student nurses and midwives: a cross sectional analysis. Nurse Education Today. 2015; 35(1):152-158.

[33] Al-Tamimi, E. M., and Al-Khawaldeh, N. A. Emotional Intelligence and Its Relation with the Social Skills and Religious Behaviour of Female Students at Dammam University in the Light of Some Variables, Canadian Center of Science and Education, International Education Studies, 2016; 9(3) 131:147.

[34] Mohzan, M. A., Hassan, N., and AbdHalil, N. The Influence of Emotional Intelligence on Academic Achievement, 6th International Conference on University Learning and Teaching (In CULT 2012) Procedia - Social and Behavioral Sciences, 2013; 90 303-312. Available online at www.sciencedirect.com

[35] Singaravelu, S. Emotional Intelligence of Student Teachers at Primary Level, Journal of All India Association for Educational Research. 2007; 19(3\&4): 49-51.

[36] Rankin, B. Emotional intelligence: enhancing values-based practice and compassionate care in nursing. Journal of advanced nursing, 2014; 69(12): 2717-25.

[37] Tafazoli, M., Hosseini, S., Sharbaf, H. A., Makarem, A., and Zadeh, S. E. A Study of relationship between emotional intelligence and clinical performance in training field in Midwifery students of Nursing and Midwifery School, 2012; 2(2): $13-18$

[38] Codier, E., Kooker, B. M., and Shoultz, J. Measuring the emotional intelligence of clinical staff nurses: an approach for improving the clinical care environment, NursAdm Q 2008; 32(1): 8-14.

[39] Gordon-Handler, L. The Relationship Between Emotional Intelligence and Clinical Performance in an Occupational Therapy Training Program. Dissertation Submitted to Northcentral University Graduate Faculty of the School of Psychology in Partial Fulfillment of the Requirements for the Degree of Doctor of Psychology, 2009.

[40] Talarico, J., Metro, D., Patel, R., and Carney, P. Emotional intelligence and its correlation to performance as a resident: A preliminary study, J ClinAnesth. 2008; 20(2): 84-89.

[41] Al-Hamdan, Z., Oweidat, I. A., Al-Faouri, I. and Codier, E. Correlating Emotional Intelligence and Job Performance Among Jordanian Hospitals' Registered Nurses, Nurs Forum. 2016 [Epub ahead of print] 
[42] Bakr, M. M., and Safaan, S. M. Emotional Intelligence: A Key for Nurses' Performance, Journal of American Science, 2012; 8(11): 385-393.

[43] Cherry, M. G., Fletcher, I., and O'Sullivan, H. Validating relationships among attachment, emotional intelligence and clinical communication, medical education. 2014; 48(10): 988-997.

[44] Hacettepe, G. E., and Kose, S. D. Evaluation of Emotional Intelligence and Communication Skills of Health Care Manager Candidates: A Structural Equation Modeling Assoc, International Journal of Business and Social Science, 2013; 4(13): $115-123$.

[45] Lee, O. S., and Ok, G. M. The Relationship between Emotional intelligence and Communication skill, Clinical competence \& Clinical practice stress in Nursing Students, Journal of the Korea Academia-Industrial cooperation Society, 2013;14(6): 2749-2759.

[46] Mi-Ran, K., Su-Jeong, H. Nursing students' emotional intelligences and coping strategies, Advanced Science and Technology Letters, Healthcare and Nursing, 2015; 88: 53-56. http://dx.doi.org/10.14257/astl.2015.88.11

[47] Cabral, A. M., and Carvalho, F. M. Emotional Intelligence and Ethics on Organizations, Open Journal of Business and Management. 2014; 2(1): 5-23. http://www.scirp.org/journal/ojbm

[48] Angelidis, J., and Ibrahim, N. A. The Impact of Emotional Intelligence on the Ethical Judgment of Managers, Journal of Business Ethics, 2011; 99(1): 111-119.

[49] Agarwal, N., and Chaudhary, N. Role of Emotional Intelligence in Ethical Decision Making a Study of Western U.P. International Journal of Management \& Business Studies, 2013; 3(1): 28-30.

[50] Miri, M. R., Kermani, T., Khoshbakht, H., and Moodi, M. The relationship between emotional intelligence and academic stress in students of medical sciences, Journal of ducation and Health Promotion, 2013 V2:40. Available at http://www.ncbi.nlm.nih.gov/pmc/articles/PMC3778639/

[51] Ghanimat, P., Koupahi, M., Partovian, S., and Fakhri, K. P. Analysis of The Relationship Between Demographic Characteristics and Emotional Intelligence in Female Student (Case Study: Islamic Azad University of Tabriz), Kuwait Chapter of Arabian Journal of Business and Management Review, 2013; 2(5): 5-16.
[52] Saeed, Y., Javadi, M ., SiratiNir, M., and Nouri, J. M. Assessment and comparison of Emotional Intelligence of Nurses in General and Intensive Care Units, Iran journal of Critical Care Nursing. 2013; 5(4): 214-221.

[53] Adeyemo, D. A. Demographic Characteristics and Emotional Intelligence among Workers in Some Selected Organisations in Oyo State, Nigeria, The Journal of Business Perspective. 2008; 12(1): 43-48.

[54] Ungur, G., and Karagozoglu, C. The Relationship between Emotional Intelligence, Social Physique Anxiety and Life Satisfaction in Physical Education and Sports Students, International Journal of Humanities and Social Science, 2013; 3(13): 115-119.

[55] Srinivasan, K., and Umesh Samuel, A. A Study on Emotional Intelligence of Staff Nurses Working In Villupuram District, IOSR Journal Of Humanities And Social Science, 2016; 21(3): 34-39.

[56] Saeid, Y., Javadi, M., Mokhtari Nouri, J., and SiratiNir, M. On the Relationship between Emotional Intelligence and Demographical Variables in Nurses, Journal of Military Medicine, 2013; 15(1):87-92.

[57] Ealias, A., and George, J. Emotional intelligence and job satisfaction: A Correlational study. The international journal research Publication's Research journal of commerce and behavioural science, 2012; 1(4) 37: 42 Available at www.theinternationaljournal.org

[58] Pande, H. S. Evaluating characteristics and emotional intelligence among workers in organizations in the state of Rajasthan, International Research Journal, 2010; 1(10): 3-6.

[59] Gangal, M. K., and Singh, J. A study of Emotional Intelligence of Teacher Trainee of Meerut City, International Journal of Behavioral, Social and Movement Sciences,2012 1(2): 99-106.

[60] Adsul, R. K. A comparative study of urban and rural students on emotional intelligence and adjustment, Indian Journal of Positive Psychology, 2013; 4(1): 169-171.

[61] Punia, S., and Sangwan, S. Emotional Intelligence and Social Adaptation of School Children, J Psychology. 2011; 2(2): 83-87. 